\title{
Financement de la culture attelée et stratégies d'équipement
}

\author{
M. Roesch ${ }^{1 *}$
}

\begin{abstract}
Mots-clés
Energie animale - Culture attelée Exploitation agricole - Service Classification - Circuit de commercialisation - Burkina Faso Cameroun - Sénégal.
\end{abstract}

\begin{abstract}
Résumé
L'analyse des conditions favorables au développement de la traction animale et celle des stratégies des agriculteurs permet de caractériser les différents types d'agriculteurs qui adoptent et développent cette technique. Trois grandes catégories apparaissent : (i) les jeunes agriculteurs entreprenants qui cherchent à développer des cultures de rente et compensent leur manque de main d'œuvre par I'utilisation de la traction bovine; l'équilibre de l'exploitation reste précaire et le maintien de la culture attelée est conditionné par la propriété d'un capital minimum sous forme de troupeau qui permet de faire face aux années déficitaires et évite de décapitaliser ; (ii) les exploitants confirmés qui ont une maîtrise technique et savent équilibrer leur gestion; la traction animale leur permet d'être moins soumis aux aléas climatiques et économiques, et de capitaliser sous forme de terre ou d'animaux; et (iii) les gros exploitants qui possèdent plusieurs attelages et en louent une partie; ils possèdent un capital terre et bétail accumulé progressivement, en partie grâce à l'utilisation de la culture attelée. Les Etats et les projets dits de développement permettaient à une large palette d'agriculteurs d'avoir accès à la traction animale. Le désengagement des Etats et la disparition des projets a freiné le développement de la traction animale, et ceci même dans les zones où se sont maintenus à la fois des cultures commerciales, une structure financière de crédit et un environnement de services favorable (marché du bétail, forgerons). Les exploitants en mesure de s'équiper et de conserver la traction animale sont aussi ceux qui réussissent à se créer un capital sous forme de bétail ou de terre. A l'heure de l'après-désengagement, la poursuite du développement de cette technique sera conditionnée par l'émergence d'un nouvel environnement de services permettant l'accompagnement de ceux qui veulent l'utiliser.
\end{abstract}

\section{INTRODUCTION}

La traction animale a été l'un des axes forts des projets de développement qui se sont succédés en Afrique de l'Ouest et centrale entre 1970 et 1990. Elle devait contribuer à la «modernisation» de l'agriculture par l'augmentation des surfaces et des rendements, et la réduction de la pénibilité du travail. Pour la «vulgariser» les projets mettaient en place le financement, du matériel, des formations et un encadrement important. Les résultats ont été très inégaux et l'analyse des nombreuses expériences de développement

\footnotetext{
1. Cirad, 73 rue Jean-François Breton, TA 60 / 15, 34398 Montpellier Cedex 5

Tél. : +33 (0)467615679 ; fax : + 33 (0)46761 4415

E-mail : marc.roesch@cirad.fr

* Adresse actuelle

French Institute of Pondicherry, 11 Saint Louis Street, Pondicherry 605 001, India

Tél. : (91 0413) 2334 168, extn 118

E-mail : marc.roesch@ifpindia.org
}

a permis de tirer une première série de conclusions sur les facteurs favorisant l'adoption de cette technique $(1,2,7,9,16)$.

Depuis la mise en place des politiques d'ajustement structurel, et de la réduction progressive des effectifs et des activités d'encadrement du monde agricole, l'environnement économique et technique a changé (vulgarisation, filières de commercialisation, financement de l'agriculture). L'environnement technique et économique de la traction animale s'est modifié (réduction de l'offre de crédits d'équipement, transferts de la production des équipements aux forgerons, démembrement des services élevages dédiés aux animaux de trait...) et, de fait, les exploitants ont été amenés à infléchir leur stratégie d'équipement ou à en inventer de nouvelles.

Ce texte présente l'évolution des modes de financement de la traction animale et des stratégies d'équipement des agriculteurs, et analyse les transformations des exploitations équipées en traction animale dans un contexte de désengagement des Etats et de libéralisation des filières de produits agricoles. Cette analyse a été réalisée à partir de la documentation existante et aussi à partir 
des données collectées sur une centaine d'exploitations équipées ou bien utilisatrices de la traction animale, réparties sur trois terrains de l'Afrique francophone où le Cirad a conduit une « étude comparative de l'évolution de la traction animale dans le contexte de désengagement des Etats » (bassin arachidier du Sénégal, zone cotonnière de l'Est Burkina et celle du Nord Cameroun).

Une analyse des pratiques d'équipement des producteurs est présentée, ainsi que les trajectoires d'exploitations associées et les éléments déterminants qui permettent aux exploitants d'acquérir, de maintenir ou de développer la traction animale malgré l'absence de politique incitative. L'évolution des facteurs considérés comme favorables à la traction animale est aussi caractérisée. Le texte conclut sur les éléments de l'environnement des exploitations sur lesquels il faudrait agir pour compenser ce désengagement de l'Etat.

\section{FACTEURS FAVORABLES AU DEVELOPPEMENT DE LA TRACTION ANIMALE}

Les régions dans lesquelles la traction animale a connu un essor durable et significatif ont en commun un certain nombre de caractéristiques. Celles-ci ont été identifiées comme des conditions qui permettent le développement de cette technique.

\section{Existence d'une production bénéficiant d'un circuit de commercialisation fiable et organisé}

Un circuit organisé et fiable satisfait à deux conditions nécessaires au développement de la traction animale : (i) celle de permettre à un exploitant d'anticiper une recette (estimant la récolte et connaissant le prix) ; (ii) celle d'obtenir les aides nécessaires à l'achat (crédit notamment) en mettant sa production en gage. Avec une culture commerciale, les exploitants minimisent les risques financiers et peuvent prendre un peu plus de risques techniques et changer leur façon de travailler.

Le cas le plus connu et parmi les plus anciens de développement de la traction animale est celui du Sénégal entre les années 1960 à $1980(4,6,17)$. Il est très nettement lié à la promotion et l'encadrement de la culture de l'arachide. Le développement le plus important en nombre d'attelages, en étendue géographique et en durée a été celui du coton (de la Guinée au Tchad pour ce qui concerne l'Afrique francophone). Aujourd'hui, la filière arachide est en crise et ne permet plus de financer l'accession à la traction animale, la filière coton par contre continue à favoriser l'équipement en traction animale (19).

Ces deux productions sont des cultures d'exportation. Mais on retrouve aussi ce lien entre développement de la traction animale et culture commercialisée pour des cultures alimentaires produites pour le marché local ou national, que la commercialisation soit organisée par l'Etat, des projets (riz, maïs ; 6) ou par des commerçants privés (oignon, souchet; 12).

\section{Existence d'un environnement technique tel que l'approvisionnement en matériel et en pièces détachées et les services de vulgarisation}

L'approvisionnement en matériel et l'encadrement technique sécurise l'exploitant et lui permet de prendre le risque d'investir. Dans les cas d'opération de développement de la traction animale lié à une culture commerciale (coton, arachide, riz...), l'encadrement technique était assuré par la même organisation que celle qui assurait la commercialisation (service de vulgarisation et société d'Etat, projet sous contrat avec l'Etat). Ces organisations assuraient également un approvisionnement en matériel et en pièces détachées.
Dans le cas de développement de productions commercialisées par des ONG ou des privés, ces derniers assuraient également ces fonctions en cas d'absence de services de l'Etat. Ainsi l'ONG Association pour la recherche et la formation en agroécologie (Arfa, Est Burkina) commercialisait le sésame et assurait l'approvisionnement et l'encadrement technique sur la production de sésame et la traction animale. Les commerçants également pouvaient très bien assurer la fonction d'approvisionnement en matériel, de crédit pour l'achat et de commercialisation de la production. C'était le cas pour la filière du souchet au Niger où les commerçants nigérians qui exportaient la production de la région de Maradi assuraient aussi l'approvisionnement en charrues fabriquées au Nigeria.

\section{Existence d'un système de crédit à moyen terme}

Dans les régions où ont été conduites les études, le niveau de revenu des exploitants agricoles et les dépenses auxquelles ils doivent faire face ne permettent pas à la majorité d'économiser suffisamment de fonds pour investir rapidement dans une paire de bœufs et du matériel de traction animale $(10,20)$. Sans système de crédit, le développement de la traction animale est possible, mais très lent.

Les Etats, les projets, les sociétés de développement, les ONG, quand ils souhaitaient promouvoir la traction animale, mettaient en place des systèmes de crédit à l'équipement. L'achat et la livraison étaient assurés soit directement par le promoteur de la technique (livraison du matériel et remboursement à la livraison de la production), soit par l'intermédiaire d'une banque nationale avec laquelle l'organisme promoteur passait un contrat (cas des banques nationales ou des caisses nationales de crédit agricole [Cnca]).

\section{Effet d'auto-entraînement}

En cours de campagne agricole un matériel peut casser, se dérégler, un animal ou un «bouvier» peut tomber malade. Face à ces difficultés un exploitant doit pouvoir trouver rapidement de l'aide pour ne pas mettre en péril sa production. Quand, dans un village, plusieurs autres exploitants sont équipés, quand il existe dans le village un forgeron qui connaît le matériel, il est possible de faire face aux incidents et de continuer à utiliser son matériel.

La culture attelée se développe mieux et plus vite dans les zones où il existe déjà une "masse critique » d'attelages, là où il est possible pour des exploitants d'acheter du matériel d'occasion « pour se faire la main », là où peut jouer l'effet de formation de proximité et d'entraide.

L'effet d'auto-entraînement est indéniable. Lors des enquêtes sur les raisons de l'achat de matériel de culture attelée, les agriculteurs qui se sont équipés par eux-mêmes évoquent comme raisons le fait d'avoir vu le matériel fonctionner chez un voisin ou dans une région voisine, ou d'avoir travaillé en culture attelée comme salarié ou avec du matériel en prêt (11).

\section{- CARACTERISTIQUES DES EXPLOITATIONS QUI ADOPTENT LA TRACTION ANIMALE DANS UN ENVIRONNEMENT FAVORABLE}

Dans un environnement favorable, les taux d'équipement en traction animale varient aujourd'hui de 20 p. 100 dans la zone cotonnière de l'Est Burkina, par exemple, à 40 p. 100 sur le plateau central, 55 p. 100 dans la zone cotonnière de l'Ouest Burkina et jusqu'à 80 p. 100 en zone arachidière du Sénégal. Les taux d'équipement ne traduisent pas la proportion effective des paysans utilisant régulièrement la traction animale. Du fait de la pratique de location elle est généralement supérieure. De plus, ces taux 
regroupent dans une même catégorie ceux qui ont un attelage monoasin et ceux qui ont une ou plusieurs paires de bœufs.

Les exploitations ayant adopté la traction animale ne sont pas structurellement, socialement et économiquement homogènes. Les enquêtes menées par le Cirad avaient pour objet de caractériser les exploitations équipées en traction animale au Cameroun, Burkina et Sénégal $(5,10,20)$. Ces observations complètent celles effectuées dans le cadre d'autres programmes de recherche à Madagascar et dans le nord du Bénin (11).

Les observations de cette étude ont mis en évidence trois grandes catégories d'agriculteurs équipés. Les critères discriminants entre ces trois catégories sont liés à l'âge, l'expérience et la capacité à se constituer un capital. Sont distingués principalement : les jeunes agriculteurs dynamiques, les exploitants confirmés, et les gros exploitants.

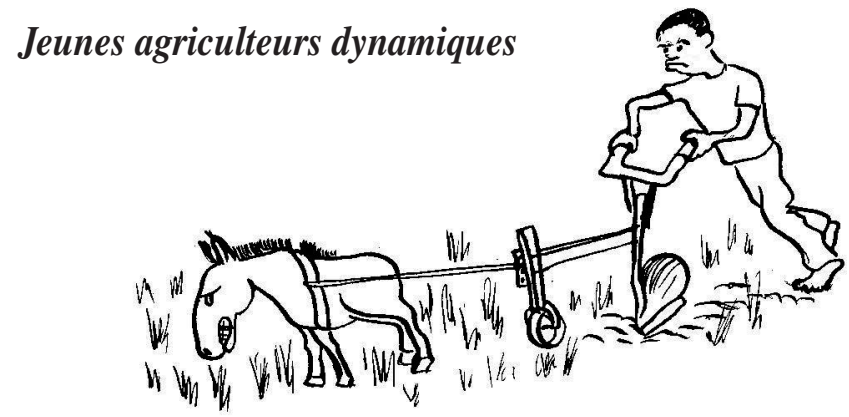

Les jeunes exploitants propriétaires de leur attelage (ânes ou paire de bœufs) ont des charges de famille relativement réduites (une épouse, quelques enfants en bas âge, quelques fois une personne âgée à charge). Leur objectif premier est de gagner de l'argent en investissant dans les cultures commerciales. Comme leur charge alimentaire n'est pas très importante, ils peuvent prendre des risques et se consacrer en priorité aux cultures de rente. Ils ont gardé des liens avec leur concession d'origine qui peut, en cas de problème, les aider à combler le déficit alimentaire.

Ils cultivent des surfaces très limitées $(<3-4$ ha) dont la moitié voire les trois quarts sont consacrés à la culture commerciale (coton, arachide). C'est le public privilégié des programmes de crédit et formation proposés par les opérateurs de développement. Ils sont considérés comme des agriculteurs « ouverts au progrès ».

Un certain nombre de handicaps fragilisent l'équilibre technique et financier de leur exploitation :

- ils manquent de main d'œuvre ; l'augmentation de superficie permise par la traction animale et l'intensification sur les cultures commerciales accroît la charge de travail pour les sarclages et la récolte dans le cas du coton. Comme la cellule familiale est réduite, ils effectuent des travaux à façon pour avoir des rentrées monétaires et payer de la main d'œuvre. Le point le plus difficile à gérer est de maintenir un équilibre entre les travaux dans leurs propres champs et ces travaux à façon ;

- ils manquent généralement de bonnes terres qui restent souvent aux mains des « anciens ». Pour compenser cette insuffisance, ils privilégient les cultures commerciales conduites de façon plus intensive. L'existence d'un organisme fournissant des intrants et du matériel à crédit leur est absolument nécessaire. Ils n'ont pas les fonds nécessaires aux investissements de campagne ;

- en raison du manque de main d'œuvre et de terres, et pour obtenir des productions vendables, ils ont souvent tendance à réduire les surfaces cultivées en céréales et autres cultures alimentaires au profit des cultures commerciales. En cas de mauvaises récoltes ils sont obligés de vendre leur force de travail, de décapitaliser ou de faire appel à la famille élargie pour assurer l'équilibre alimentaire de leur exploitation.
Malgré ces handicaps, en cas de réussite des cultures commerciales pendant quelques années, ces exploitants sont en mesure de commencer un processus d'accumulation (constitution d'un capital terre ou une épargne sous forme de troupeau) qui permettra de surmonter les années difficiles. Mais l'équilibre est délicat. Les mauvaises années, de nombreux jeunes sont amenés soit à mobiliser leur épargne soit à s'endetter lourdement. Ceci les conduit à travailler davantage sur les terres des autres les campagnes suivantes pour rembourser les dettes. Dans les cas extrêmes, ils revendent leur attelage et retournent à la culture manuelle. De fait, la plupart des jeunes exploitants qui se maintiennent en traction animale sont ceux qui présentent une résilience plus forte grâce à un capital terre ou un troupeau reçu en héritage lors de leur installation.

\section{Exploitants confirmés}

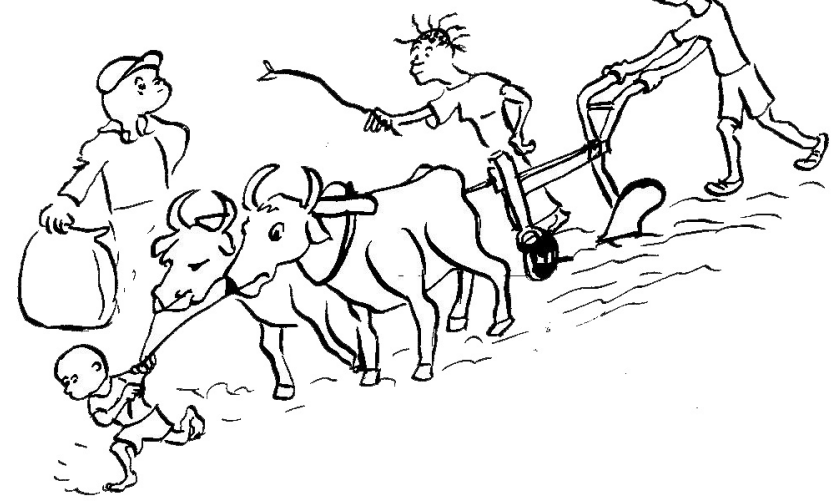

La deuxième catégorie comprend des exploitants qui ont déjà acquis un équipement de traction minimum et qui ont une bonne maîtrise de leur système de culture. Le complément d'équipement est possible parce qu'ils satisfont aux conditions suivantes :

- terres disponibles pour un agrandissement de l'exploitation (2 à 3 ha de plus, soit un total de 4 à 6 ha) ;

- main d'œuvre familiale permettant d'affecter un ou plusieurs enfants à la conduite des animaux (exploitations de 3 à 4 actifs au moins) ;

- main d'œuvre suffisante pour assurer les sarclages ou activité génératrice de revenus pour financer les travaux de désherbage ;

- un équilibre entre culture commerciale, vivrière et des activités annexes (maraîchage, artisanat, salariat) garantissant une autosuffisance alimentaire et des réserves vivrières en année normale.

Ces producteurs, qui arrivent à équilibrer leur budget, se constituent un capital progressivement, chaque fois qu'une bonne année le leur permet (sous forme d'animaux essentiellement). L'équipement en traction animale reste un investissement lourd car ils visent la traction bovine (encadré 1).

Dans la plupart des cas rencontrés lors des enquêtes, le premier équipement est obtenu à la suite d'un don d'une ONG, d'un crédit d'un projet ou d'une institution de microfinance, ou bien il a été offert par un parent. Il est très rare qu'un exploitant puisse acheter une paire de bœufs à partir uniquement de ses économies tirées des revenus de sa production agricole.

Des analyses de trajectoire d'exploitations mettent en évidence le fait que l'acquisition de matériel agricole les fait changer d'échelle à la fois en termes de surface (ils doublent, voire triplent les surfaces exploitées si les terres sont disponibles) et en termes de rendement (les travaux du sols améliorent la conservation de l'eau, la traction animale permet le transport de matières organiques).

Ce type d'exploitation dégage des excédents presque tous les ans. En cas de difficultés, elle n'est pas obligée de procéder à une décapitalisation (vente d'animaux) pour équilibrer l'exploitation. 


\section{Encadré 1}

\section{QUELQUES COMMENTAIRES ET ORDRES DE GRANDEUR}

Les besoins financiers pour l'acquisition d'un âne et d'une charrue asine sont très différents de ceux nécessaires à une paire de bœufs et une charrue bovine. Les prix moyens relevés au Burkina Faso et au Cameroun sont sensiblement les mêmes :

- pour un âne, 30000 à 40000 Fcfa ;

- pour un «petit » bœuf de trait, 100000 à 120000 Fcfa .

- pour un bœuf de trait à la revente, 150000 à 200000 Fcfa ;

- pour une charrue asine, 20000 à $65000 \mathrm{Fcfa}$;

- pour une charrue bovine, 30000 à $85000 \mathrm{Fcfa}$.

Les relevés faits au Burkina et Cameroun mettent en évidence des capacités d'autofinancement (marge brute des activités exercées + dons perçus + intérêts sur l'épargne - remboursements des crédits de consommation et de régulation datant de plus d'un an - dépenses familiales totales) de 10000 à $50000 \mathrm{Fcfa} / \mathrm{an}$ pour un jeune agriculteur, 100000 à 200000 Fcfa pour les exploitants confirmés et plus de $200000 \mathrm{Fcfa}$, pouvant dépasser 1 million Fcfa pour un gros exploitant (Raubec, 2001, Esat ; Videault, 2001, Istom). Au vue de ces prix il apparaît très nettement qu'un jeune agriculteur ou un agriculteur confirmé ne peut accéder que difficilement à la traction animale sans aide extérieure (projet, ONG, famille). D'autre part, une mauvaise récolte épuise très rapidement la capacité d'autofinancement et oblige quelques fois à décapitaliser. Si le capital cheptel est suffisant, les animaux de trait ne sont pas vendus et l'exploitant garde sa capacité de production. Dans le cas contraire, les animaux sont vendus en premier, le matériel en second.

L'équilibre se fait en vendant des céréales, donc par ajustement de la gestion des stocks de céréales.

Deux éléments essentiels caractérisent ce type d'exploitation : la maitrise des techniques culturales et de la traction animale d'un coté et leur capacité de gestion de l'autre (gérer l'équilibre entre culture vivrière et culture de rente, maîtrise de dépenses et mise en place d'une accumulation de capital souvent sous forme de bétail permettant de poursuivre les investissements).

\section{Gros exploitants}

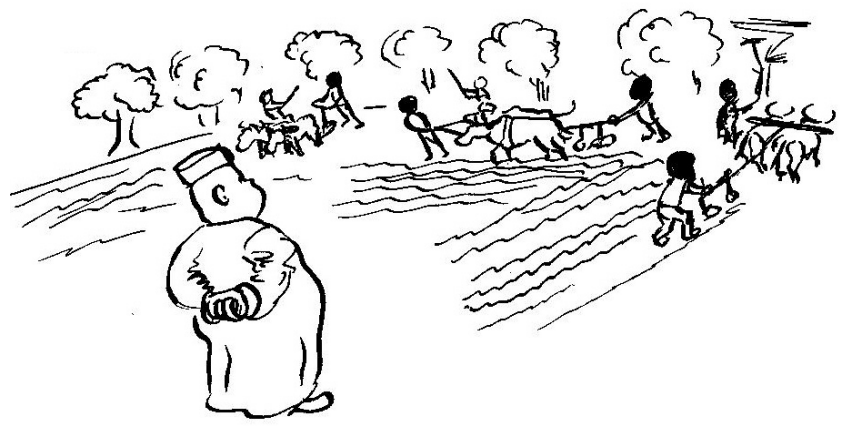

Cette troisième catégorie d'exploitants comprend généralement des chefs de grandes concessions ou familles qui disposent à la fois de surfaces importantes ( 8 à 15 ha et davantage) et de la main d'œuvre facile à mobiliser. Ils disposent également de revenus d'élevage (parce qu'ils sont propriétaires de troupeaux) ou d'autres ressources (commerce, maraîchage, transport, etc.). Certains ont saisi l'opportunité des projets pour s'équiper et multiplier les attelages. Aujourd'hui, ils sont souvent en mesure de financer sur leurs fonds propres tout ou partie des équipements et de puiser dans leurs troupeaux les animaux de trait.
Ces gros exploitants disposent à la fois du capital (troupeau) du travail (main d'œuvre familiale importante) et de la terre. Ils ont l'obligation d'approvisionner le grenier de la famille élargie. Ainsi les cultures alimentaires sont souvent ajustées à la taille de la famille. L'importance des cultures commerciales dépend des conditions de mises en marché et du prix des intrants. Ils investissent dans des activités de diversification exigeantes en capital (embouche, élevage de volailles, vergers...) ou bien dans l'achat d'équipement qui leur permet d'améliorer la productivité du travail sur l'exploitation (tracteur, motopompe...).

\section{Agriculteurs équipés en traction animale légère}

Il existe une catégorie d'exploitants équipés en traction asine dont la composition familiale et la classe d'âge sont proches de celles des exploitants confirmés. Le gain de productivité du travail par ce type d'équipement est limité. Ainsi au Nord Cameroun, une exploitation en culture manuelle cultive 0,4 ha/actif contre 0,7 pour une exploitation en traction asine et 0,8 à 1,1 pour une exploitation en traction bovine. Le travail en traction asine permet de cultiver une superficie légèrement plus importante qu'en travail manuel (c'est le sarclage qui représente le goulot d'étranglement). La qualité du travail n'est que légèrement améliorée. La profondeur de travail et la surface labourable par un attelage asin sont bien inférieures à celles d'une paire de bœufs. Aussi assiste-t-on à une amélioration limitée de la production. La capacité de capitaliser, d'accumuler sous forme de bétail, n'est pas plus importante en traction asine qu'en culture manuelle, et bien inférieure à celle des exploitants équipés en traction bovine. De ce fait, ce type d'exploitant n'a pas été inclus dans la présente typologie, car les problèmes d'accès à la traction bovine se posent de la même façon pour ces exploitations que pour celles en culture manuelle, techniquement et économiquement (5).

\section{- EXEMPLE DE TYPOLOGIE D'EXPLOITATIONS DANS L'EST BURKINA FASO}

Le tableau I présente une typologie des exploitations dans la zone cotonnière de l'Est Burkina enquêtée par Ilboudo et Videault (5, 20). Il met en évidence les points suivants :

- parmi les jeunes exploitants autonomes, il y a nettement deux sous-catégories, ceux qui ont une petite exploitation (3 à 3,5 ha), sans capital (peu d'animaux), et ceux qui héritent d'un troupeau, de terres (6 à 7 ha). En contrepartie, ces derniers ont aussi la charge d'une parenté plus importante (4 à 6 actifs agricoles contre 2 à 4 pour les précédents);

- dans la tranche d'âge 35 à 50 ans, on retrouve cette séparation entre ceux qui ont réussi à accumuler en tirant parti d'un héritage (4 à 7 ha, 12 bovins et 30 caprins en moyenne) et ceux qui sont restés sur des exploitations modestes ( 2 à 4 ha, pas ou peu de bovins, une quinzaine de petits ruminants). Chez ces derniers on relève un début d'accumulation par les animaux, mais pas vraiment d'accumulation sur la terre (on reste à 1 ha par actif) ;

- ce n'est que dans la tranche des 50 ans et plus que l'on peut remarquer un début d'accumulation sur la terre (de 6 à 17 ha) qui s'ajoute à des troupeaux conséquents (plus de 7 bovins et 30 ovins).

Les utilisateurs de traction bovine sont dans les catégories ayant du capital (les 35 - 50 ans avec terres et troupeaux) et chez les seniors. Quelques jeunes exploitants ont également un attelage bovin; ce sont ceux qui ont bénéficié d'une opération de crédit en 19981999. 


\section{Tableau I}

Typologie des exploitations du village de Diapaga dans la zone cotonnière de l'Est Burkina Faso (Videault, 2001, Istom ; Ilboudo, 2001, IDR)

\begin{tabular}{|c|c|c|c|c|c|}
\hline Age moyen & $\begin{array}{l}\text { Nb. d'actifs } \\
\text { agricoles }\end{array}$ & $\begin{array}{l}\text { Superficie } \\
\text { cultivée (ha) }\end{array}$ & $\begin{array}{l}\text { Nb. de bovins } \\
\text { d'élevage }\end{array}$ & $\begin{array}{l}\text { Nb. de petits } \\
\text { ruminants }\end{array}$ & $\begin{array}{l}\text { Nb. de bovins } \\
\text { de trait }\end{array}$ \\
\hline \multirow[t]{2}{*}{$\begin{array}{l}\text { De } 20 \text { à } 25 \text { ans } \\
(9 \cup P *)\end{array}$} & 2 à 4 (5 UP) & 3 à 3,5 & 1 UP/9 (11 têtes) & 0 à 19 (moy. = 9) & $\begin{array}{l}2 \text { UP avec } 2 \text { bovins de trait } \\
3 \text { UP sans bovin de trait } \\
1 \text { âne/UP }\end{array}$ \\
\hline & 4 à 6 (4 UP) & 6 à 7,25 & $\begin{array}{l}2 \text { à } 23 \text { têtes } \\
\text { (moy. = 10) }\end{array}$ & 22 à 34 (moy. = 30) & $\begin{array}{l}1 \text { UP avec } 4 \text { bovins de trait } \\
2 \text { à } 3 \text { ânes/UP }\end{array}$ \\
\hline $\begin{array}{l}\text { De } 26 \text { à } 35 \text { ans } \\
\text { (8 UP) }\end{array}$ & 2 à 4 & 3 à 4,5 & 5 UP/8 ont 4 têtes & 0 à 21 (moy. = 11) & $\begin{array}{l}2 \text { UP avec } 2 \text { bovins de trait } \\
\text { Toutes avec } 1 \text { ou } 2 \text { ânes }\end{array}$ \\
\hline \multirow[t]{2}{*}{$\begin{array}{l}\text { De } 35 \text { à } 50 \text { ans } \\
(8 \text { UP) }\end{array}$} & 2 à 4 (4 UP) & 2,6 à 3,75 & $\begin{array}{l}1 \text { bovin pour } \\
\text { un seul exploitant }\end{array}$ & 0 à 35 (moy. = 17) & $\begin{array}{l}\text { Pas de bovin de trait } \\
1 \text { UP avec } 1 \text { âne } \\
1 \text { UP avec } 2 \text { ânes }\end{array}$ \\
\hline & 4 à 6 (4 UP) & 4 à 6,5 & $\begin{array}{l}3 \text { à } 36 \text { têtes } \\
(\text { moy. }=12)\end{array}$ & 5 à 57 (moy. = 30) & $\begin{array}{l}0 \text { à } 4 \text { bovins de trait } \\
(\text { moy. }=2) \\
1 \text { à } 5 \text { ânes/UP }(\text { moy. }=2)\end{array}$ \\
\hline \multirow[t]{2}{*}{$\begin{array}{l}\text { Plus de } 50 \text { ans } \\
(6 \text { UP) }\end{array}$} & 4 à 8 (4 UP) & 5 à 8,75 & 3 à 72 têtes & 27 à 34 & $\begin{array}{l}2 \text { UP avec } 2 \text { bovins de trait } \\
2 \text { UP sans bovin de trait } \\
1 \text { à } 6 \text { ânes/UP }\end{array}$ \\
\hline & 7 et 10 (2 UP) & 9,5 et 17 & 35 et 68 têtes & 90 et 100 & $\begin{array}{l}4 \text { à } 8 \text { bovins de trait/UP } \\
2 \text { à } 4 \text { ânes/UP }\end{array}$ \\
\hline
\end{tabular}

* Unité de production

\section{CYCLE DE VIE DES UNITES}

\section{DE PRODUCTION ET TRACTION ANIMALE}

Les effets de la traction bovine se situent aussi dans le processus de capitalisation, comme cela est mis en évidence ci-après dans l'analyse du cycle de vie des unités de production. La typologie présentée ci-dessus ne sera pertinente que si elle permet de traduire des trajectoires d'exploitation et de resituer les exploitations les unes par rapport aux autres en se basant sur ces trajectoires. D'autre part, comme Perrot et coll. l'ont souligné, « les typologies ne peuvent tenir durablement ce rôle d'outil au service du développement que dans la mesure où elles conservent leur pertinence au cours du temps ce qui impliquent qu'elles évoluent parallèlement aux exploitations » (8).

Chacun des types d'exploitation a été placé sur un graphe qui comporte en abscisse l'âge de l'exploitant et en ordonnée son capital. Un tel graphe traduit ce que l'on appelle un cycle de vie. L'âge est un critère synthétique qui prend en compte le fait qu'avec l'âge un exploitant a de plus en plus d'enfants en mesure de travailler sur l'exploitation et qu'il acquiert expérience et technicité. Le capital mis en abscisse peut être constitué de terre (c'est le cas de certaines zones du Nord Cameroun et du Bénin) ou de bétail (cas de l'extrême Nord Cameroun, du Burkina et du Niger), ou d'une combinaison des deux.

La tendance commune à l'ensemble des exploitations est d'accumuler du capital avec l'âge. On peut tracer un lien entre les trois types présentés ci-dessus et parler de filière d'évolution (8). Mais cette évolution n'est pas linéaire, elle se fait par marche d'escalier.

\section{Première marche : accès à la traction animale et zone de fragilité}

Le passage de la culture manuelle à la culture attelée bovine se fait soit en douceur par un passage à la traction asine (peu de capital animal, peu d'accroissement de superficie, mais aussi peu d'accroissement de production et donc de capitalisation possible), soit d'un coup par achat, crédit ou don d'une paire de bœufs. En début de carrière l'équilibre des exploitations est fragile. Suivant l'importance des biens transmis ou de la dotation de départ, certains jeunes exploitants accèdent directement à des niveaux de capitalisation qui leur permettent de se mettre à l'abri des aléas de la production. On peut donc tracer une zone de fragilité en dessous de laquelle les exploitants peuvent n'avoir que leur attelage comme capital, capital qu'ils vendent en cas de difficulté (figure 1, ligne pointillée).

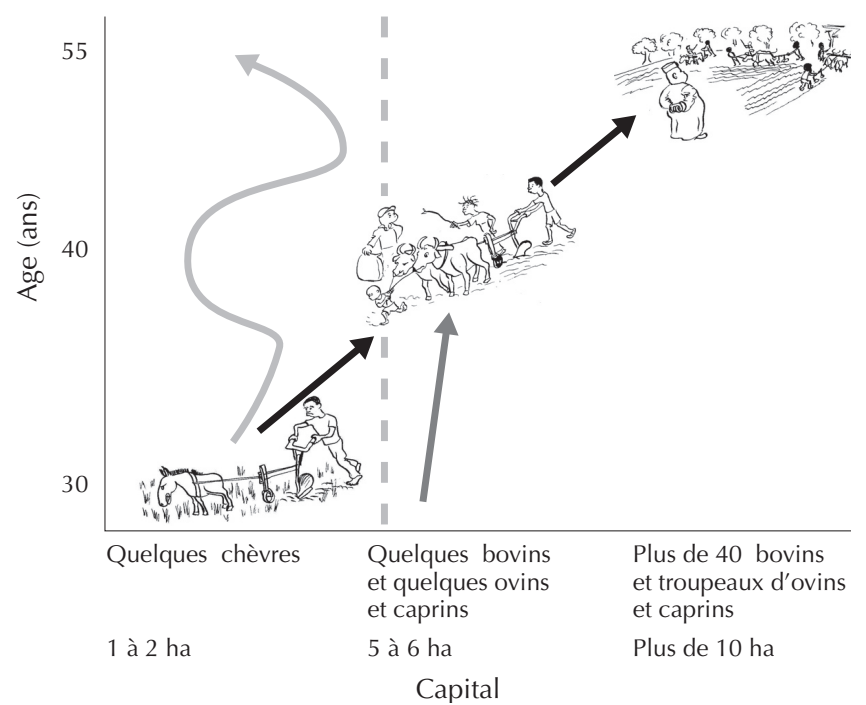

Figure 1 : cycle de vie d'exploitations utilisant la traction animale. 


\section{Deuxième marche : professionnalisation et risque de retour en arrière}

Tirer parti d'une paire de bœufs, l'utiliser pour faire des travaux de qualité et savoir l'entretenir est un nouveau défi. Un attelage permet l'accroissement de production par extensification dans un premier temps, puis par intensification. Elle oblige à réorganiser le travail dans l'exploitation (spécialiser un ou plusieurs enfants à la conduite des animaux, gérer les sous-produits agricoles, collecter et stocker du fourrage, la matière organique...). Si les aspects techniques sont maîtrisés, après quelques années, l'exploitant peut accroître son troupeau, exploiter plus de terre, acheter une deuxième paire (nouvelle marche d'escalier).

Mais la progression suivant un schéma de capitalisation croissante est loin d'être évidente. Une mauvaise récolte peut conduire à une décapitalisation du cheptel de trait et un retour à un niveau d'équipement plus bas. Bon nombre d'exploitations n'arrivent pas à franchir une seconde fois le pas et restent jusqu'à la fin de leur vie dans une progression sinueuse à un bas niveau de capitalisation.

\section{Troisième marche : «sous-traitance »}

L'exploitant utilise de moins en moins les attelages par lui-même et les confie à ses enfants, sa parenté, ses voisins. La capitalisation se fait à partir des revenus tirés de la location ou de ce que lui donnent ses « dépendants » sous forme de bétail ou par le stockage des céréales produites. Les observations de terrain ont permis de voir deux grandes tendances à ce niveau d'accumulation. Ceux qui privilégient la production de céréales et ceux qui mettent l'accent sur le coton $(11,20)$. A la fin des années 1990 et au début des années 2000, le prix attractif du coton a permis une accumulation à partir des revenus du coton. Dans un certain nombre de cas on voit apparaitre une accumulation sous d'autres formes (commerce, construction et location de maison, achat de matériel de transformation, de motopompe, etc.).

\section{Quatrième marche : retraite}

L'exploitant cède son capital à ses enfants et se replie sur une petite surface, un petit troupeau. Ses enfants subviennent à ses besoins.

\section{- LES EXCLUS DE LA CULTURE ATTELEE}

Les blocages les plus fréquemment observés en matière d'accès à la traction animale ont quatre origines.

\section{Précarité}

Une large majorité d'exploitations est constituée de petites structures familiales en culture manuelle. Elles utilisent les possibilités offertes par les organismes qui encadrent les cultures commerciales, mais sur des surfaces faibles et complémentaires de leurs cultures alimentaires prioritaires. Les ressources financières sont toujours insuffisantes et l'équilibre alimentaire reste fragile. Le peu de capital disponible, sous forme d'animaux, ne peut être gagé dans des opérations d'endettement dont l'issue est incertaine. La traction bovine représente un gros investissement, hors de leur portée.

Si une «opération promotionnelle » d'acquisition de matériel de culture attelée leur est proposée et qu'ils la considèrent sans risque (don de matériel, opération lancée par des ONG, ou si on leur propose des crédits identifiés comme probablement non remboursables), ces exploitants peuvent se porter volontaire à un programme de traction animale. Mais souvent dès la première difficulté, ils refusent de rembourser le crédit et revendent les animaux de trait. Le matériel est revendu ou reste inutilisé (20).

\section{Exploitations seules face aux caisses de crédit}

De nombreuses exploitations, parce qu'elles ne sont pas intégrées dans une filière de commercialisation organisée, ou parce qu'elles ne veulent pas ou ne peuvent pas produire des cultures de rente, n'ont pas accès aux crédits. Elles peuvent avoir les potentialités et les compétences pour valoriser la traction animale (superficie, main d'œuvre, troupeaux à proximité), mais les banques (nationales, privées) ou les systèmes de microfinance sont réticents à leur proposer des crédits parce que :

- elles sont souvent peu monétarisées et ont des difficultés à présenter des garanties matérielles vendables en cas de non remboursement ;

- les produits qu'elles pourraient vendre pour rembourser les prêts (céréales, bétail) sont sujets à des fluctuations de prix importantes et en conséquence à fort risque pour un banquier ;

- les taux d'intérêts pratiqués pour les crédits à moyen terme (2 à 3 ans) sont prohibitifs et le crédit court terme ne peut être que le complément d'un apport personnel conséquent ; une capacité d'autofinancement suffisante reste une nécessité.

\section{Absence de compétences techniques}

Dans les zones où la traction animale est peu présente, bon nombre d'exploitants hésitent à se lancer dans l'aventure. Ceux qui l'osent ont tous acquis une expérience, soit dans un centre de formation (opérations menées par les projets et $\mathrm{ONG}$ ), soit lors de migration temporaire dans des zones à forte implantation de traction animale où ils ont vu et pratiqué la culture attelée.

\section{Marché du bétail peu actif}

Les exploitants investissent dans un animal d'autant plus facilement qu'ils savent pouvoir le revendre si nécessaire à un prix égal ou supérieur au prix d'achat. Les exploitants ont connaissance de cela et ceux qui investissent comptent exploiter cette possibilité.

Dans certaines zones ou localités, le marché de bétail est aux mains d'un petit nombre de commerçants qui, pour des raisons géographiques (zones enclavée), logistiques (monopole du transport), ou alliances avec les postes de contrôle de la douane ou de la police, peuvent empêcher l'ouverture à la concurrence. Ils s'entendent pour maintenir les prix à un niveau très bas et s'arroger les marges (témoignage d'exploitants et Hadi [3]). Ce sont ces marges qui permettraient aux exploitants d'investir dans la traction animale. Ce type de marché est un frein au développement de la culture attelée.

\section{- QUELLES STRATEGIES ADOPTER POUR DEVELOPPER LA CULTURE ATTELEE SUITE AU DESENGAGEMENT DE L'ETAT ET DES OPERATEURS?}

Il n'y aura pas de retour vers des projets de développement de la traction animale, et les services de l'Etat n'ont plus les techniciens, vétérinaires et animateurs pour lancer des vulgarisations sur ce thème. Dès lors, trois cas de figures se présentent plus ou moins favorables au maintien de la technique.

\section{Existence d'une filière organisée, présence d'un organisme de financement}

Dans une filière organisée, l'approvisionnement en intrant est assuré soit par les organisations paysannes, soit par le commerçant collecteur, et le prix d'achat à la récolte est connu d'avance, en principe avant les semis. Il existe encore des zones où coexistent une filière 
organisée (coton, riz...) et un organisme de financement. Il s'agit du cas le plus favorable pour développer la traction animale. Les organismes qui gèrent la filière assurent aussi l'approvisionnement en intrants et en matériel agricole. Ils assurent aussi directement ou indirectement la fonction de crédit, soit en donnant le matériel et en se remboursant progressivement lors de l'achat des productions agricoles (cas de la Société de développement du coton [Sodecoton] au Cameroun [15]), soit en sous-traitant la partie crédit à une banque avec laquelle ils passent des accords (cas du contrat de la Société nationale pour la promotion des produits agricoles et de la Fédération des caisses d'épargne et de crédit agricole mutuel [Sonapra - Fececam] au Bénin, et celui de la Société des fibres textiles et de la Banque agricole et commerciale [Sofitex - Bacb] au Burkina Faso). Dans ce contexte les exploitants s'adressent préférentiellement à l'organisme de commercialisation qui assure le crédit ou à l'organisme bancaire qui a passé un accord avec l'organisme de commercialisation (11). Si un accord n'a pu se faire entre l'organisme de crédit et la structure de commercialisation, les organisations de producteurs tentent de jouer les intermédiaires pour organiser le marché financier ou créer un organisme de financement intermédiaire (cas de la filière oignon au Nord Cameroun, de l'association Tin Tua au Burkina). C'est dans ces contextes que l'on voit apparaître une classe d'agriculteurs gros propriétaires qui bénéficie des appuis de la filière, des crédits, et qui investit les organisations paysannes.

\section{Existence d'une filière organisée, absence d'opérateur de financement proche}

Dans ce cas l'exploitant est obligé d'apporter la totalité des fonds de départ pour l'animal (ou les animaux) et le matériel, ou de faire appel à la famille ou aux prêteurs informels. Ceci est souvent problématique. L'existence d'une culture de rente rassure les éventuels prêteurs (la famille, les amis, les usuriers, les commerçants fournisseurs de matériel). Le capital social sera le deuxième élément déterminant. Dans ce contexte, les exploitants qui auront accès à la traction animale sont donc les agriculteurs producteurs d'une culture de rente et bénéficiant d'un bon capital social, ce qui signifie un gros troupeau, des terres, un commerce...

\section{Absence de filière organisée, présence d'une offre en crédit}

Les banques financent très rarement la traction animale; quand elles le font, c'est pour de très gros exploitants présentant des garanties sérieuses (commerçants, fonctionnaires). Les organismes de microcrédit sont également très réticents à faire des prêts à moyen terme ( 2 à 5 ans). Quelques fois, même s'ils le veulent, ils n'y sont pas autorisés par la réglementation bancaire ; en effet, pour faire des crédits à moyen terme, il faut avoir des ressources monétaires à moyen terme (épargne bloquée, dépôt à terme...). Les taux d'intérêt en vigueur dans ces organismes (1,5 à 3 p. 100 par mois) renchérissent énormément les prêts à moyen terme (56 à 70 p. 100 d'intérêts sur trois ans). Peu d'exploitants sont en mesure de supporter ces taux et les risques d'impayés croissent avec la durée du prêt. Ceux qui peuvent avoir accès à ces prêts ont obligatoirement de solides garanties et des revenus autres que les simples cultures pluviales (élevage, commerce, salariat, artisanat, cultures de contre-saison). La stratégie développée par ceux qui veulent accéder à la traction animale dans un tel contexte est de faire appel à l'organisme financier pour des prêts de 8 à 12 mois. Ils remboursent à partir des revenus tirés des activités non agricoles ou de contre-saison en complément de ceux d'une culture de rente. A titre d'exemple, à Botou (Est Burkina en zone sahélienne) les remboursements de prêt ont été faits grâce à des revenus d'activités secondaires (salariat, petit commerce, maraîchage) pour la moitié des exploitants et à l'arachide pour l'autre moitié (13). Une autre stratégie consiste à revendre un animal sur deux après une année d'utilisation et d'engraissement. Dans ce cas également l'existence d'un marché au bétail actif est un avantage. L'emprunt à la caisse de crédit permet d'acheter un animal, une activité secondaire permet de rembourser ce premier prêt. Puis, après une année (et en ayant cultivé avec du matériel emprunté), l'exploitant vend cet animal de trait, et avec cette somme et un second prêt il peut acheter deux animaux pour la culture attelée. La revente de l'un d'eux et un troisième prêt permettent d'acheter un peu de matériel, etc. Les exploitants qui sont en mesure de réaliser ce type d'opération doivent disposer d'un capital minimum pour être crédible auprès des organismes financiers (capital social ou cheptel). Ils doivent également ne pas être fragiles, c'est-à-dire ne pas être en déficit vivrier au moindre problème climatique.

\section{Absence de filière organisée, absence d'organisme de financement}

Dans ce contexte, seules les grosses exploitations, dans lesquelles un ou plusieurs membres ont eu l'occasion d'expérimenter la traction animale dans un autre contexte (migration généralement), font la démarche d'acquérir des animaux de trait et du matériel (zone sahélienne de Botou, Est Burkina, avant l'opération de crédit de 1998 ; 20). Bien souvent il s'agit de dons ou de prêts venant de la famille ou d'ONG caritatives. Elles arrivent à maintenir la culture attelée en s'appuyant sur une bonne maîtrise des techniques de cultures. Mais dans de telles conditions, la culture attelée est très anecdotique (moins de 5 p. 100 des exploitations équipées) et réservée aux exploitations qui ont été en mesure de saisir une opportunité.

\section{DISCUSSION}

L'analyse des stratégies des exploitants agricoles pour acquérir et continuer à utiliser la traction animale met en évidence qu'il s'agit d'une étape décisive et difficile pour l'unité de production qui dépend fortement du contexte technique, économique et organisationnel. Cependant, un plus grand nombre d'exploitations peuvent accéder à la traction animale à partir du moment où des services et appuis sont en place, comme, pour citer les plus importants :

- un système de crédit par les institutions de microfinance, adossé à une filière de commercialisation qui permet de garantir le remboursement du crédit ; mais pour cela il doit y avoir un accord avec la filière de commercialisation pour assurer le remboursement et limiter les crédits à un an ou moins ;

- une formation et un appui technique à l'utilisation de la traction animale, rôle que s'attribuent les projets, les sociétés de développement, les organisations paysannes et les ONG ;

- un appui technique pour la fabrication et l'entretien du matériel (réseaux de forgerons) et le suivi sanitaire des animaux (services vétérinaires).

L'absence de tout appui à la promotion et accompagnement de la traction animale a pour effet de cantonner cette technique aux exploitations les mieux pourvues en capital terre et cheptel, et à celles qui disposent de ressources financières suffisantes pour cet investissement. D'autre part, l'utilisation de cette technique, quand elle est bien maîtrisée, permet d'accroître l'accumulation de capital, soit sous forme de terre, soit sous forme de produits agricoles.

La terre : l'étude a montré que la traction animale s'accompagne d'une augmentation des superficies mises en culture quand cette augmentation est possible. La traction animale entraîne-t-elle une accélération de la colonisation des terres ou une réduction 
des temps de jachère tout en continuant à favoriser une exploitation extensive ? Il semblerait que non. L'augmentation de superficie cultivée se trouve vite limitée par la capacité de l'exploitant à mâ̂triser les mauvaises herbes ? L'accumulation du capital terre sera conditionnée par la capacité à mobilier la main d'œuvre nécessaire à l'entretien.

Il est à noter que, dans un deuxième temps, quand il y a saturation foncière, la traction animale permet l'intensification. Le labour améliore la pénétration de l'eau dans le sol et donc l'implantation des cultures en début de saison. Des cultures mieux installées incitent les exploitants à y mettre de l'engrais. L'investissement engrais y est moins risqué. Des animaux de traction, c'est aussi de la production de fumier et la possibilité de le transporter jusqu'aux parcelles. Il y a valorisation du capital terre par des pratiques d'intensification.

Les produits agricoles : L'étude a également montré que la traction animale peut se maintenir si elle s'accompagne d'une accumulation de capital sous forme de cheptel ou de céréales stockées dans les greniers. L'accumulation sous forme de cheptel conduit à un accroissement des troupeaux et une utilisation plus importante des pâturages. Ce type d'évolution se doit d'être réfléchie et accompagnée pour arriver à une gestion raisonnée et non anarchique de l'espace pastoral. Dans les zones de cultures où se développe cette forme de capitalisation par le bétail, la gestion des pâtures devient difficile.

La traction animale a également un effet sur l'extension des cultures céréalières. Soit directement, soit parallèlement à l'extension des cultures de coton, les céréales permettent de valoriser l'arrière effet de la fumure coton (Sud Mali, Nord Bénin, Ouest Burkina...). Ceci peut provoquer une forte augmentation de l'offre de céréales sur les marchés et est susceptible d'exacerber la désorganisation déjà existante des filières d'approvisionnement en céréales en concurrençant les zones exclusivement céréalières (18).

Si la relance de la traction animale paraît être une nécessité pour permettre aux exploitants d'accroître leur production, pour réduire la pénibilité du travail, pour permettre une intensification des cultures, elle n'est pas sans risque :

- risque financier pour le producteur ;

- risque de dégradation pour les ressources sylvopastorales en cas de forte augmentation du cheptel de trait paysan.

Pour faire face à ces risques, elle nécessiterait des services et des mesures d'accompagnement :

- appuis à la commercialisation des produits (pour financer l'acquisition de la traction, pour permettre l'écoulement des produits agricoles produits « en plus »);

- mise en place de crédits adaptés à l'acquisition des animaux de trait et du matériel ;

- appuis techniques (approvisionnement en matériel et en formation à l'utilisation) ;

- appuis en matière de gestion des exploitations (14) ;

- appuis au marché du bétail ;

- appuis à la gestion des terroirs.

La construction de ces appuis, de ces services et leur articulation représentent un défi qui est lancé aux organisations qui souhaitent promouvoir la traction animale.

\section{BIBLIOGRAPHIE}

1. BORDET D., HAVARD M., 1998. La traction animale au Burkina Faso. Effets des interventions du gouvernement dans le secteur du machinisme agricole. Montpellier, France, Cirad-sar, 26 p.

2. GERDAT, 1982. Actes séminaire Conditions de développement de la culture attelée, Montpellier, France, 14-18 sept. 1981. Paris, France, Gerdat, 198 p.

3. HADI M., 2000. Contribution du Système d'information sur le marché à bétail (Simb) du Niger. In : Conférence Perspectives agricoles de l'Afrique de l'Ouest, Bamako, Mali, 7-9 fév. 2000. Niamey, Niger, ministère des Ressources animales, 26 p.

4. HAVARD M., FAYE A., 1988. Eléments d'analyse de la situation actuelle de la culture attelée au Sénégal : perspectives d'études et de recherches. In : Starkey P., Ndiamé F., éds, Animal power in farming systems. Eschborn, Allemagne, GTZ, p. 241-252.

5. ILBOUDO I., 2001. Etude socio-économique des pratiques agricoles et évaluation du passage de la culture manuelle à la culture attelée dans la Tapoa, Burkina Faso: cas des zones de Botou et Boaguidigou. Mémoire IPR Katibougou, Burkina Faso. Bobo Dioulasso, Burkina Faso, IDR, 96 p.

6. LHOSTE P., 1983. Développement de la traction animale et évolution des systèmes agropastoraux au Sine Saloum. In : Actes du séminaire du groupe de travail Economie rurale, Montpellier, France, 13-17 sept. 1982. Montpellier, France, Gerdat, p. 35-50.

7. LHOSTE P., 1995. la traction animale en Afrique: aspects socioéconomiques. In : Tisserand J.L., Pearson A., Eds, Draught animal power in Europe and the Mediterranean basin. Rome, Italy, FAO/OAA, p. 23-30.
8. PERROT C., PIERRET P., LANDAIS E., 1995. L'analyse des trajectoires des exploitations agricoles. Une méthode pour actualiser les modèles typologiques et étudier l'évolution de l'agriculture locale. Econ. rurale, 228 : $35-47$.

9. PINGALI P., BIGOT Y., BINSWANGER H.P., 1987. Mécanisation agricole et évolution des systèmes de production en Afrique subsaharienne. Baltimore, MD, USA, Johns Hopkins University Press, 224 p. (World Bank res. publ.)

10. RAUBEC S., 2001. Le financement de la traction animale en zone de savane cotonnière du Nord-Cameroun dans un contexte de libéralisation. Mémoire, Esat 1, Cnearc, Montpellier, France, 209 p. + annexes

11. RENARD O., 1999. Sous quelles conditions les systèmes financiers décentralisés parviennent-ils à financer l'investissement agricole ? Etude d'impact du crédit moyen terme à l'équipement de la Fececam dans le cadre de la privatisation de la filière coton au Bénin. Mémoire, Ensa, Rennes, France, 110 p. + annexes

12. ROESCH M., 1982. Le développement de la culture attelée dans le département de Maradi au Niger. In : Actes du séminaire du groupe de travail Economie rurale, Montpellier, France, 13-17 sept. 1982. Montpellier, France, Gerdat, p. 51-76.

13. ROESCH M., 2001. Financer la traction animale, le cas des systèmes agraires de l'Est Burkina. Montpellier, France, Cirad-tera, 15 p. (Rapport de mission $n^{\circ}$ 52-02)

14. ROESCH M., VALL E., KENIKOU MOUNKAMA C., HAVARD M., 2002. Recettes, dépenses et crédits, comment accorder les rythmes? Ce que peut apporter le conseil d'exploitation à la gestion de la trésorerie des ménages agricoles et aux institutions de microfinance. In : Séminaire Le financement de I'agriculture familiale dans un contexte de libéralisation : quelle contribution de la microfinance? Dakar, Sénégal, 21-24 janv. 2002. Montpellier, France, Cirad, 17 p. 
15. ROESCH M., WAMPFLER B., KENIKOU MOUNKAMA C., 2003. Financer la campagne agricole : quels appuis, quelles évolutions? Le cas du Nord Cameroun. In : Actes colloque Savanes africaines : des espaces en mutation, des acteurs face à de nouveaux défis, Garoua, Cameroun, 27-31 mai 2002. Montpellier, France, Cirad.

16. STARKEY P., Ed., 1998. Integrating mechanisation into strategies for sustainable agriculture. Wageningen, The Netherlands, CTA, 24 p.

17. STARKEY P., 2000. The history of working animals in Africa. In: Blench R.M., MacDonald K., Eds, The origins and development of African livestock: archaeology, genetics, linguistics and ethnography. London, UK, University College London Press, p. 478-502.

\section{Summary}

Roesch M. Financing of Draft Animal Cultivation and Strategies for Equipment

The analysis of conditions favorable for developing draft animal power and farmers' strategies helped characterize the several types of farmers who adopted and developed this technique. Three major groups are highlighted: (i) the young enterprising farmers, who seek to develop cash crop production and compensate the lack of labor by the use of draft cattle; the stability of the farm remains fragile and to maintain draft animal cultivation, farmers need to own a minimum capital in the way of a herd so as to better face poor years and avoid dipping into capital; (ii) the confirmed farmers, who have mastered the technique and know how to balance their budgets; animal traction helps them be less subjected to climatic and economic hazards, and capitalize on land and animals; (iii) the big farmers, who own several animal teams and lend a few; their capital of land and animals increases progressively, in part thanks to draft animal cultivation. The States and so-called development projects enabled a wide range of farmers to access to animal traction. States disengagement and projects suppression slowed down animal power development. This even occurred in the areas where commercial crops, credit financial structures, and a favorable services environment (cattle markets, blacksmiths) were maintained. Farmers who managed to acquire implements and keep animal traction are also those who managed to build a capital in the form of cattle or land. In the context of post-disengagement, pursuing the development of this technique will have to coincide with the creation of a new services set-up to provide the support needed to those using it.

Keywords: Animal power - Draught animal cultivation - Farm Services - Classification - Marketing channel - Burkina Faso Cameroon - Senegal.
18. TEME B., SANOGO O., BOUGHTON D., 1995. Le maïs dans les systèmes de production du sud du Mali : historique et perspectives. In Production et valorisation du maïs à l'échelon villageois en Afrique de I'Ouest. Montpellier, France, Cirad-sar, p. 173-179.

19. VAlL E., LhOSTE P., ABAKAR O., DONGMO N., AIME L., 2003. Ia traction animale dans le contexte en mutation de l'Afrique subsaharienne : enjeux de développement et de recherche. Agricultures, 12 : 219-226

20. VIDEAULT S., 2001. Analyse des besoins et des stratégies de financement de la traction animale des exploitations agro-pastorales de la province de la Tapoa, Burkina Faso, Pays gourmanché. Mémoire fin d'études, Istom Paris, France.

\section{Resumen}

Roesch M. Financiamiento de los cultivos con yunta y estrategias para equiparlos

El análisis de las condiciones favorables al desarrollo de la tracción animal y de las estrategias de los agricultores permite la caracterización de los diferentes tipos de agricultores que adoptan y desarrollan esta técnica. Aparecen tres grandes categorías: (i) los jóvenes agricultores emprendedores, que tratan de desarrollar los cultivos de renta y compensan la falta de mano de obra con el uso de la tracción bovina; el equilibrio de la explotación es precario y el mantenimiento del cultivo con yunta está condicionado por la posesión de un capital mínimo, bajo la forma del hato, que permite enfrentar los años de déficit y evitar la pérdida de capital; (ii) los productores confirmados, que dominan la técnica y saben equilibrar su manejo; la tracción animal les permite estar menos sometidos a los cambios climáticos y económicos, así como capitalizar bajo forma de tierra o de animales; y (iii) los grandes productores que poseen varias yuntas y que alquilan una parte; éstos poseen un capital de tierra y de ganado acumulado progresivamente, en parte gracias al uso del cultivo con tiro. Los Estados y los proyectos Ilamados de desarrollo permiten a una amplia gama de agricultores el acceso a la tracción animal. El desentendimiento de los Estados y la desaparición de los proyectos han frenado el desarrollo de la tracción animal, incluso en las zonas en donde se han mantenido al mismo tiempo los cultivos comerciales, una estructura financiera de crédito y un medio de servicios favorable (mercado de ganado, herreros). Los productores con capacidad para equiparse y para conservar la tracción animal, son los mismos que logran crear un capital bajo la forma de ganado o de tierras. En la época del post desentendimiento, la continuidad del desarrollo de esta técnica estará condicionada por el surgimiento de un nuevo medio de servicios, que permita el acompañamiento de los que quieran utilizarla.

Palabras clave: Energía animal - Cultivo a tracción - Explotación agraria - Servicio - Clasificación - Corrient de mercadeo Burkina Faso - Camerún - Senegal. 